\title{
Comments on therapy option for primary spontaneous pneumothorax
}

\author{
Zixuan Chen ${ }^{1,2}$, Weijun Zhao ${ }^{3}$, Linyao Wang ${ }^{1}$, Ke Jin ${ }^{1}$, Jianfei Shen ${ }^{1}$ \\ ${ }^{1}$ Department of Cardiothoracic Surgery, Taizhou Hospital of Zhejiang Province Affiliated to Wenzhou Medical University, Linhai, China; \\ ${ }^{2}$ Department of Thoracic Surgery, The Affiliated Hospital of Medical School, Ningbo University, Ningbo, China; ${ }^{3}$ Department of Thoracic Surgery, \\ Ningbo First Hospital, Ningbo, China \\ Correspondence to: Jianfei Shen. Department of Cardiothoracic Surgery, Taizhou Hospital of Zhejiang Province Affiliated to Wenzhou Medical \\ University, No.150 Ximen Street, Linhai, China. Email: jianfei051@163.com.
}

Submitted Apr 25, 2020. Accepted for publication Aug 13, 2020.

doi: $10.21037 /$ jtd-20-1759

View this article at: http://dx.doi.org/10.21037/jtd-20-1759

Nowadays, removal of air in the pleural cavity is a recognized treatment strategy for primary spontaneous pneumothorax. It is divided into interventional treatment and conservative treatment according to whether there is clinical intervention, but the choice of interventional treatment and conservative treatment is still controversial. The British Thoracic Society guidelines recommend interventional treatment of pneumothorax with a depth of $2 \mathrm{~cm}$ or more, including acupuncture pumping, chest tube drainage, and surgery. The preferred drainage exhaust is small diameter chest tube. If pneumothorax persists, further surgical treatment is required (1). However, complications such as pain, bleeding, tissue damage and infection are the risks of interventional therapy. The British Thoracic Society guidelines recommend conservative treatment of pneumothorax less than $2 \mathrm{~cm}$ in depth, including analgesia and oxygen intake (1). Conservative treatment mainly relies on the reabsorption of gas by pulmonary capillaries to eliminate pneumothorax (2), which requires outpatient follow-up and reexamination without intervention, thus greatly reducing the risk of tissue damage, bleeding, infection and other factors, which is a convenient treatment strategy. However, conservative treatment should be alert to the high-risk complications such as persistent air leakage and tension pneumothorax (3). At the same time, compliance of outpatient patients should be recognized as an important factor affecting follow-up monitoring. At present, studies on interventional treatment and conservative treatment of primary spontaneous pneumothorax are mainly retrospective studies, with different conclusions and lack of studies with high level of evidence (4). Therefore, we urgently need a well-designed clinical randomized controlled trial to compare the benefits and risks of conservative treatment and interventional treatment, and to provide a reference for the treatment of primary spontaneous pneumothorax.

Fortunately, on January 30, 2020, Brown et al. reported the results of the study on the comparison between interventional therapy and conservative therapy for moderate to large primary spontaneous pneumothorax (5). The study was a multicenter, randomized controlled trial involving 316 patients aged 14 to 50 with moderate to large primary pneumothorax, who were randomized into either the interventional treatment group $(n=154)$ or the conservative treatment group $(\mathrm{n}=162)$. After treatment, all patients were evaluated at 24-72 hours, 2 weeks, 4 weeks, and 8 weeks of follow-up. Chest radiograph is the main examination method, and the imaging cure rate of pneumothorax is the main observation index in this study. The secondary observation index includes pain degree, recurrence rate, complications, etc. Finally, a binomial non-inferiority test and sensitivity analysis were used to compare the differences between the two groups. Through this study, we can find that during the 8-week followup period, $85 \%$ of patients in the conservative treatment group did not receive further interventional therapy, and the pulmonary reexpansion was favorable. Reexpansion within 8 weeks occurred in 129 of 131 patients $(98.5 \%)$ with interventional management and in 118 of 125 (94.4\%) with conservative management [risk difference, -4.1 percentage points; $95 \%$ confidence interval $(\mathrm{CI}),-8.6$ to $0.5 ; \mathrm{P}=0.02$ 
for noninferiority]. Meanwhile, conservative treatment is just as effective at reducing symptoms as intervention. The conservative group also had shorter hospital stays, fewer complications, earlier return to work and a lower recurrence rate. The results indicated that conservative therapy of primary spontaneous pneumothorax was noninferior to interventional therapy.

Brown et al.'s study has important clinical significance and provides high-level evidence for the clinical treatment of pneumothorax. However, the research is not perfect, and there are still many things to think about and explore. Chest X-ray is a routine examination for outpatient diagnosis and evaluation of spontaneous pneumothorax. Studies have shown that about $15 \%$ of primary spontaneous pneumothorax has emphysema pneumothorax, but chest $\mathrm{X}$-ray is not sensitive to the diagnosis of emphysema pneumothorax (6). Therefore, in the study of Brown et al., chest radiographs were used for the diagnosis of primary spontaneous pneumothorax, which could not fully identify emphysema pneumothorax and could not fully evaluate the underlying pulmonary diseases of patients, which may cause some deviation of the study results. However, computed tomography (CT) is more sensitive to the diagnosis of emphysema than chest radiographs (7). Therefore, CT can be used as the diagnosis and follow-up method of primary spontaneous pneumothorax, which is conducive to the identification of patients' underlying pulmonary diseases (such as small-diameter pulmonary bulla and emphysema) and the improvement of research quality. On the other hand, smoking is an important risk factor for primary spontaneous pneumothorax. In a 10-year retrospective study, Bense et al. found that $88 \%$ of patients with primary spontaneous pneumothorax had a history of smoking. Compared with non-smokers, the risk of pneumothorax increased 9 times in female smokers and 22 times in male smokers (8). In Brown et al.'s study, smoking was not matched between the two groups, and smoking rates were significantly higher in the intervention group than in the conservative group $(61.8 \%$ vs. $52.5 \%)$. At the same time, the number of smoking per year in the interventional treatment group (mean $8.1 \pm 23.3$ packs/year $v s$. mean $4.8 \pm 7.8$ packs/year) was significantly higher than that in the conservative treatment group. Thus it could be speculated that different smoking conditions may affect the healing and recurrence of primary spontaneous pneumothorax patients, resulting in data deviation and affecting the accuracy of the results. Therefore, a good match of smoking history and other pneumothorax risk factors between the two groups will help to indicate the accuracy of the study results. Several authors have stated the association between cannabis smoking and the risk of primary spontaneous pneumothorax $(9,10)$. Bisconti et al. have demonstrated the presence of cannabinoids and particular pathologic alterations in lung tissues of young cannabis smokers operated for PSP, supporting the correlation between this disease and cannabis abuse and suggesting spontaneous pneumothorax "secondary to cannabis" as a new nosological entity (9). So, together with tobacco smoke, the authors should mention cannabis smoking too, because cannabis smoking can be a contributing factor "resulting in data deviation and affecting the accuracy of the results". Surgical treatment of primary spontaneous pneumothorax is safe and feasible (11), and is an ideal option for interventional pneumothorax treatment. Olesen $e t a l$. compared the efficacy of thoracoscopic surgery and thoracic tube drainage for primary pneumothorax in a multicenter randomized controlled study, and the results showed that the recurrence rate in the surgery group was significantly lower than that in the thoracic tube group $(13 \%$ vs. $34 \%, \mathrm{P}=0.0012$ ) (12). However, interventional therapy was only small-bore thoracic tube drainage without surgical treatment, which increased the risk of recurrence to some extent in the study of Brown et al. If surgery is taken as a part or even the main part of interventional therapy, the research results may be different from the current ones, and it is worth further study in the future.

In conclusion, Brown et al.'s study confirmed that conservative treatment of young, moderate to large primary spontaneous pneumothorax patients was a safe and effective treatment strategy, providing strong evidence for clinical guidelines and of important clinical significance. However, the interventional and conservative treatment of primary spontaneous pneumothorax is a complicated problem, and there are still many factors and problems worth reflection and exploration.

\section{Acknowledgments}

Funding: None.

\section{Footnote}

Provenance and Peer Review: This article was a free submission to the journal. The article was sent for external peer review.

Peer Review File: Available at http://dx.doi.org/10.21037/jtd- 
20-1759

Conflicts of Interest: All authors have completed the ICMJE uniform disclosure form (available at http://dx.doi. org/10.21037/jtd-20-1759). JS serves as an unpaid section editor of Fournal of Thoracic Disease from Jan 2020 to Dec 2021. The other authors have no conflicts of interest to declare.

Ethical Statement: The authors are accountable for all aspects of the work in ensuring that questions related to the accuracy or integrity of any part of the work are appropriately investigated and resolved.

Open Access Statement: This is an Open Access article distributed in accordance with the Creative Commons Attribution-NonCommercial-NoDerivs 4.0 International License (CC BY-NC-ND 4.0), which permits the noncommercial replication and distribution of the article with the strict proviso that no changes or edits are made and the original work is properly cited (including links to both the formal publication through the relevant DOI and the license). See: https://creativecommons.org/licenses/by-nc-nd/4.0/.

\section{References}

1. MacDuff A, Arnold A, Harvey J, et al. Management of spontaneous pneumothorax: British Thoracic Society Pleural Disease Guideline 2010. Thorax 2010;65 Suppl 2:ii18-ii31.

2. Northfield TC. Oxygen therapy for spontaneous pneumothorax. Br Med J 1971;4:86-8.

3. Simpson G, Vincent S, Ferns J. Spontaneous tension pneumothorax: what is it and does it exist? Intern Med J

Cite this article as: Chen Z, Zhao W, Wang L, Jin K, Shen $J$. Comments on therapy option for primary spontaneous pneumothorax. J Thorac Dis 2020;12(11):6416-6418. doi: $10.21037 /$ jtd-20-1759
2012;42:1157-60.

4. Ashby M, Haug G, Mulcahy P, et al. Conservative versus interventional management for primary spontaneous pneumothorax in adults. Cochrane Database Syst Rev 2014;2014:CD010565.

5. Brown SGA, Ball EL, Perrin K, et al. Conservative versus Interventional Treatment for Spontaneous Pneumothorax. N Engl J Med 2020;382:405-15.

6. Lyra Rde M. Etiology of primary spontaneous pneumothorax. J Bras Pneumol 2016;42:222-6.

7. Silva CI, Marchiori E, Souza Júnior AS, et al. Illustrated Brazilian consensus of terms and fundamental patterns in chest CT scans. J Bras Pneumol 2010;36:99-123.

8. Bense L, Eklund G, Wiman LG. Smoking and the increased risk of contracting spontaneous pneumothorax. Chest 1987;92:1009-12.

9. Bisconti M, Marulli G, Pacifici R, et al. Cannabinoids Identification in Lung Tissues of Young Cannabis Smokers Operated for Primary Spontaneous Pneumothorax and Correlation with Pathologic Findings. Respiration. 2019;98:503-11.

10. Underner M, Urban T, Perriot J, et al. Pneumothorax spontané et emphysème pulmonaire chez les consommateurs de cannabis. Rev Pneumol Clin 2018;74:400-15.

11. Son BS, Kim DH, Lee SK, et al. Small Single-Incision Thoracoscopic Surgery Using an Anchoring Suture in Patients With Primary Spontaneous Pneumothorax: A Safe and Feasible Procedure. Ann Thorac Surg 2015;100:1224-9.

12. Olesen WH, Katballe N, Sindby JE, et al. Surgical treatment versus conventional chest tube drainage in primary spontaneous pneumothorax: a randomized controlled trial. Eur J Cardiothorac Surg 2018;54:113-21. 